\title{
Preanesthesia Evaluation and Reduction of Preoperative Care Costs
}

\author{
Márcia Rodrigues Neder Issa, TSA ${ }^{1}$, Núbia Faria Campos Isoni, TSA ${ }^{2}$, Alessandra Marinho Soares ${ }^{3}$, \\ Magda Lourenço Fernandes, TSA 4
}

Summary: Issa MRN, Isoni NFC, Soares AM, Fernandes ML - Preanesthesia Evaluation and Reduction of Preoperative Care Costs.

Background and objectives: Preanesthesia evaluation (PAE) is fundamental in the preparation of a surgical patient. Among its advantages is the reduction of preoperative care costs. Although prior studies had observed this benefit, it is not clear whether it can be taken into consideration among us. The objective of the present study was to compare the costs of preoperative care performed by the surgeon with estimated costs based on PAE. In parallel, we compared the American Society of Anesthesiologists (ASA) physical status classification determined by the anesthesiologist with that estimated by other specialists.

Methods: Two hundred patients scheduled for elective surgery or diagnostic procedures whose preoperative care was made by the surgeon underwent PAE after hospital admission. The anesthesiologist determined which ancillary exams or referrals necessary for each patient. The number and cost of ancillary exams or referrals requested by the anesthesiologist were compared with those of the preoperative preparation. The ASA classification according to the anesthesiologist was also compared to that of the physician in charge of the consultation.

Results: Out of 1,075 ancillary exams performed, $55.8 \%$ were not indicated, which corresponded to $50.8 \%$ of the total cost of exams. The anesthesiologist considered that 37 patients $(18.5 \%)$ did not require exams. The cost of surgeon-oriented preoperative care was higher than that based on the preanesthesia evaluation and this difference in costs was statistically significant $(p<0.01)$. In $9.3 \%$ of the patients discordance in ASA classification according to the specialist was observed.

Conclusions: Preoperative care based on judicious preanesthesia evaluation can result in significant reduction in costs when compared to that oriented by the surgeon. Good concordance in ASA classification was observed.

Keywords: Anesthesia; Preoperative Care; Laboratory Techniques and Procedures; Costs and Cost Analysis.

[Rev Bras Anestesiol 2011;61(1): 60-71] OElsevier Editora Ltda.

\section{INTRODUCTION}

Preanesthesia evaluation (PAE) is defined as the process of clinical evaluation that precedes anesthetic care, which are necessary for the realization of the surgery or non-surgical procedure ${ }^{1}$. Among the advantages of PAE are included a reduction in morbidity and increase in the quality of the anesthetic-surgical procedure. When performed prior to the date of the surgery PAE also promotes a reduction in patient anxiety ${ }^{2}$, cancelation of surgeries ${ }^{3,4}$, and costs due to ancillary exams and subspecialty consultations requested in the preoperative period ${ }^{5,6}$. Although excessive request of ancillary exams is an universal conduct most studies evaluating costs were performed abroad whose reality not always applies to

Received from Santa Casa de Belo Horizonte (SCBH), Belo Horizonte, MG, Brazil.

1. Anesthesiologist SCBH, Health Executive MBA.

2. Anesthesiologist SCBH.

3. Health Executive MBA. ICU Nurse of SCBH.

4. Anesthesiologist of SCBH and Hospital das Clínicas of UFMG, Specialty in Intensive Care, Responsible for the CET of SCBH, Scientific Director of SAMG.

Submitted on July 7,2010.

Approved on August 12, 2010.

Correspondence to:

Dra. Márcia Rodrigues Neder Issa

Rua Nilton, 276

Santa Lúcia

30360-200 - Belo Horizonte, MG, Brazil

E-mail: fernandesmagda@yahoo.com.br our case. The objective of the present study was to evaluate the costs of preoperative care performed by the surgeon compared to the care based on the PAE in patients in a philanthropistic institution.

\section{METHODS}

This is an observational study approved by the Ethics Committee of the Institution. After signing the informed consent, 200 patients scheduled for elective surgery or diagnostic procedures were evaluated by the primary physician assisted by the anesthesiologist. Only patients of a specific health insurance who did not undergo PAE in the outpatient clinic were selected. Preanesthesia evaluation was performed only after hospital admission on the day of the surgery. After anamnesis and physical examination the anesthesiologist filled out two forms. In form I (Preanesthesia evaluation) he recorded the physical status of the patient according to the American Society of Anesthesiologists (ASA) classification ${ }^{7}$, the ancillary exams indicated based on directives of the Anesthesiology Department of the Institution (Table I), and referrals requested according to his clinical judgment. In form II (surgeon's care), ancillary exams performed and referrals in the preoperative care, as well as physical status classification contained in the medical report were recorded. Referrals were those performed by non-anesthesiologists to evaluate the preoperative clinical condition. The data of 
Table I - Directives for Requesting Preoperative Exams used by the Anesthesiology Department on the Institution*

\begin{tabular}{|c|c|c|}
\hline Physical Status ${ }^{\star \star}$ & Associated Disease or Condition & Preoperative Exams \\
\hline \multirow{3}{*}{ ASA I } & Age $>65$ years & Hemoglobin, hematocrit \\
\hline & Age $>60$ years & Blood glucose, creatinine \\
\hline & Age $>45$ years (male) or $>55$ years (female) & ECG \\
\hline \multirow{5}{*}{ ASA II } & Diabetes mellitus & Hemoglobin, hematocrit, blood glucose, creatinine, $\mathrm{Na}^{+}, \mathrm{K}^{+}, \mathrm{ECG}$ \\
\hline & Cardiovascular disease & $\begin{array}{l}\text { ECG, creatinine } \\
\text { Consider chest X-ray }\end{array}$ \\
\hline & Use of diuretics & $\mathrm{Na}^{+}$and $\mathrm{K}^{+}$ \\
\hline & Pulmonary disease & Consider chest X-ray \\
\hline & Chronic smoking (more than 20 pack/year) & ECG, Consider chest X-ray \\
\hline ASA III & $\begin{array}{l}\text { Cardiovascular disease, diabetes mellitus, or } \\
\text { respiratory disease }\end{array}$ & $\begin{array}{l}\text { Hemoglobin, hematocrit, blood glucose, creatinine, } \mathrm{Na}^{+} \text {and } \mathrm{K}^{+} \text {, } \\
\text { ECG, chest X-ray }\end{array}$ \\
\hline$\overline{\text { ASA II e III }}$ & With other diseases & Exams according to the disease \\
\hline \multirow{7}{*}{ ASA I,II e III } & Suspected anemia & Hemoglobin, hematocrit \\
\hline & Major surgeries & \\
\hline & Use of anticoagulants & \\
\hline & Use of phytotherapy & \\
\hline & History of bleeding & Coagulogram \\
\hline & Major surgeries & \\
\hline & Surgeries with increased risk of bleeding & \\
\hline
\end{tabular}

both forms were compared to evaluate the discrepancies. To calculate costs the lower prices of exams performed by service providers of the health insurance plan and the value paid for referrals were recorded. In the analysis of the exams performed, those performed within one year, except those that can show short-term changes such as glucose levels in diabetics, or complete blood count in patients with bleeding were considered valid. Exams that could be directly related to surgical propaedeutics, such as liver function tests, carcinoembryonic antigen (CEA), and urine exams were not considered either.

Patients undergoing emergency surgeries, those admitted to the hospital on a date prior to the surgery, patients unable to answer medical questions and the person responsible for the patient also could not provide the necessary information, patients who did not have with them the exams or medical reports performed in the preoperative care were excluded.

To calculate the sample size we obtained the mean and standard deviation $(743.8 \pm 64.8)$ of the number of patients of the health insurance carrier selected who underwent surgeries in the institution during the prior 10 months. Using the calculation for finite populations and non-replacement samples procedures we obtained $n=200$, which guarantees $95 \%$ confidence and a maximal error of $4.8 \%$. We used descriptive statistics to analyze the data. Analysis of the difference of the mean costs per patient between the preparation performed by the surgeon and that proposed by the PAE was verified by the Wilcoxon test due to the lack of normalcy of the data (by the Kolmogorov-Smirnov test) adopting a level of significance of $5 \%$. Data were analyzed by the Excel (Microsoft Corporation) and Statistical Package for Social Sciences (SPSS Inc. version 17.0) programs.

\section{RESULTS}

Two hundred patients were evaluated from October 17 to December 23, 2009. Table II shows the demographic data of the patients. The frequency of procedures performed, within clinical perspectives is show in Table III.

Ancillary exams were compared according to whether it was performed and indicated. A total of 1,075 ancillary exams were performed by 200 patients. Comparing the exams performed (preparation by the surgeon) to those indicated by the anesthesiologist (PAE) it was observed that $55.8 \%$ of the exams performed were not indicated and 37 patients $(18.5 \%)$ did not need any ancillary exam, and all of them were classified as ASA I. Figure 1 shows the exams performed in the surgeon-oriented care, and Figure 2 shows the exams indicated by the PAE.

The costs with ancillary exams performed in the surgeonoriented preparation and those indicated by the PAE were compared (Table IV). The costs of unnecessary exams (55.8\% of the total number of exams performed) represented $50.8 \%$ of the total cost of exams.

One hundred and eighty-one patients (90.5\%) underwent specialty consultations during the surgeon-oriented preoperative care. The anesthesiologist considered only six (3.31\% of consultations performed or $3 \%$ of the total of patients) of those consultations necessary. Table $\mathrm{V}$ shows the total cost of the preparation made by the surgeon including tests and specialized referrals compared to the total cost proposed by the PAE, including the outpatient preanesthesia consultation.

The mean value of the total cost per patient in surgeonguided preoperative care was $\mathrm{R} \$ 70.29$ (standard deviation of $\mathrm{R} \$ 27.75$, median $=67.05$ ) and that of the PAE was $R \$ 52.63$ (standard deviation $R \$ 24.82$, median $=52.06$ ). 
Table II - Demographic Data of 200 Patients who were Evaluated

\begin{tabular}{cl}
\hline Gender & $\mathrm{n}(\%)$ \\
Male & $143(71.5)$ \\
Female & $57(28.5)$ \\
Age (years) & \\
Up to 18 & $6(3.0)$ \\
19 to 60 & $121(60.5)$ \\
Above 60 & $73(36.5)$ \\
\hline
\end{tabular}

Table III - Frequency of Surgical or Diagnostic Procedures Among the Different Departments in the 200 Patients Evaluated

\begin{tabular}{|c|c|c|}
\hline & $\mathrm{n}$ & $\mathrm{N}(\%)$ \\
\hline Ophthalmology & & $36(18.0)$ \\
\hline Cataract surgery & 25 & \\
\hline Blepharoplasty & 9 & \\
\hline Dacryocystorhinostomia & 1 & \\
\hline Vitrectomy & 1 & \\
\hline Endoscopy & & $32(16.0)$ \\
\hline Colonoscopy & 32 & \\
\hline Orthopedics & & $28(14.0)$ \\
\hline Lower limb surgery & 17 & \\
\hline Upper limb surgery & 10 & \\
\hline Surgery of the spine & 1 & \\
\hline Gynecology and mastology & & $26(13.0)$ \\
\hline Surgery of the uterus & 14 & \\
\hline Breast surgery & 6 & \\
\hline Laparoscopy & 3 & \\
\hline Oophorectomy & 2 & \\
\hline Vulvar surgery & 1 & \\
\hline Vascular surgery & & $23(11.5)$ \\
\hline $\begin{array}{l}\text { Varicose vein surgery and/or } \\
\text { saphenectomy }\end{array}$ & 23 & \\
\hline General surgery & & $16(8.0)$ \\
\hline Videolaparoscopic cholecystectomy & 10 & \\
\hline Herniorrhaphies & 6 & \\
\hline Otorhinolaryngology & & $10(5.0)$ \\
\hline Septoplasty & 5 & \\
\hline Ear surgery & 4 & \\
\hline Adeno-amygdalectomy & 1 & \\
\hline Urology & & $8(4.0)$ \\
\hline Prostate surgery & 4 & \\
\hline Bladder surgery & 4 & \\
\hline Proctology & & $7(3.5)$ \\
\hline Hemorrhoidectomy & 5 & \\
\hline Colectomy & 2 & \\
\hline Thoracic surgery & & $6(3.0)$ \\
\hline Thoracotomy or thoracoscopy & 5 & \\
\hline Tracheal surgery & 1 & \\
\hline Plastic surgery & & $5(2.5)$ \\
\hline Mammaplasty and/or abdominoplasty & 3 & \\
\hline Lesion exeresis and/or graft & 2 & \\
\hline Neurosurgery & & $3(1.5)$ \\
\hline Cranioplasty & 1 & \\
\hline Stereotaxic biopsy & 1 & \\
\hline Radiculotomy & 1 & \\
\hline
\end{tabular}

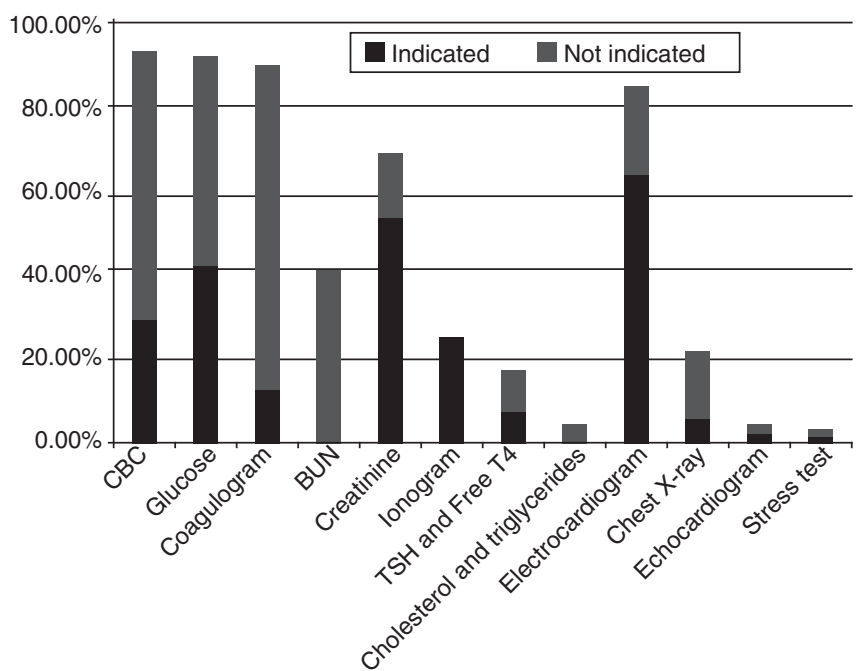

Figure 1 - Exams Performed in Surgeon-guided Care Distributed According to the Indication of the Anesthesiologist in the 200 Patients Evaluated.

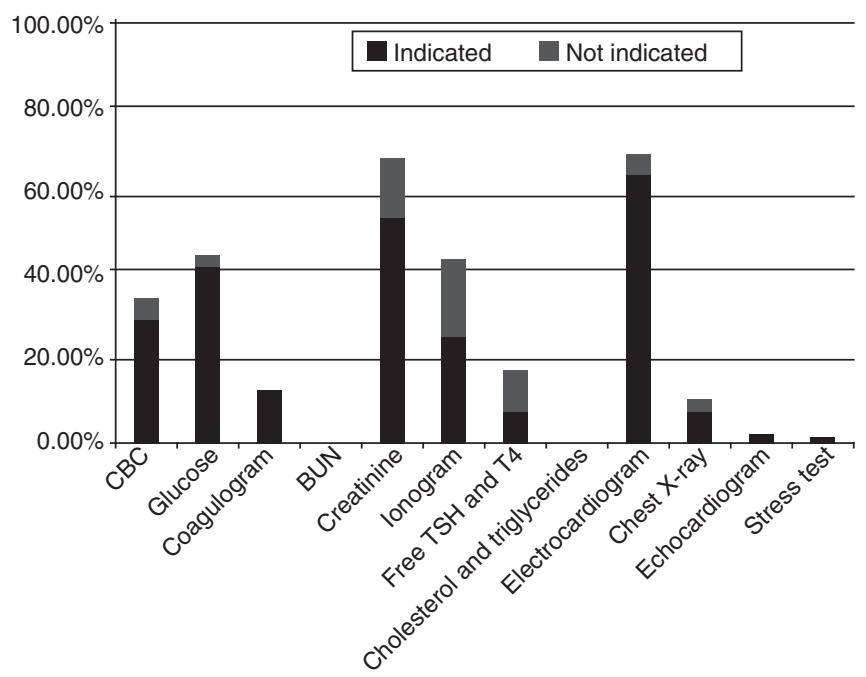

Figure 2 - Exams Indicated be the Anesthesiologist Distributed According to Whether they were Performed in the Surgeon-oriented Care in the 200 Patients Evaluated.

Comparing the two mean costs by the Wilcoxon test a statistical difference was observed $(p<0.01)$. The estimated economy was $25.11 \%$. From the data for calculation of the sample size, it is known that a mean of 743.80 patients of the selected health insurance carrier are admitted for elective surgeries every month. Therefore, the estimated monthly economy totaled $R \$ 13,128.07$, while the annual economy was $\mathrm{R} \$ 157,536.84$.

The physical status classification according to the ASA as determined by the physician responsible for the specialty consultation was compared to that determined by the anesthesiologist. Out of 200 patients, 181 patients underwent specialized consultations. In nine patients (4.5\%),the physical status classification was not on the medical record. Among 172 patients who were classified, in 16 (9.3\%) their classification disagreed 
Table IV - Comparison of the Number and Cost of Exams Performed in Surgeon-Guided Preoperative Care with those of the Preanesthesia Evaluation in the 200 Patients Evaluated

\begin{tabular}{|c|c|c|c|c|c|c|c|}
\hline & \multicolumn{2}{|c|}{ Surgeon-guided care } & \multicolumn{2}{|c|}{ Preanesthesia evaluation } & \multicolumn{2}{|c|}{ Difference } & \multirow[b]{2}{*}{ Cost $(\mathrm{R} \$)$} \\
\hline & $\mathrm{n}$ & Cost $(\mathrm{R} \$)$ & $\mathrm{n}$ & Cost (\$) & $\mathrm{n}$ & $\%$ & \\
\hline $\mathrm{CBC}$ & 185 & 758.50 & 57 & 233.70 & 128 & 69,1 & 524.80 \\
\hline Blood glucose & 184 & 340.40 & 81 & 149.85 & 103 & 55,9 & 190.55 \\
\hline Coagulogram* & 180 & $1,530.00$ & 24 & 204.00 & 156 & 86,6 & $1,326.00$ \\
\hline BUN & 79 & 146.15 & 0 & 0.00 & 79 & 100,0 & 146.15 \\
\hline lonogram** & 46 & 391.00 & 50 & 425.00 & -4 & $-8,6$ & -34.00 \\
\hline Creatinine & 136 & 251.60 & 106 & 196.10 & 30 & 22,0 & 55.50 \\
\hline TSH and free T4 & 34 & 699.04 & 14 & 287.84 & 20 & 58,8 & 411.20 \\
\hline Cholesterol and triglycerides & 8 & 182.24 & 0 & 0.00 & 8 & 100,0 & 182.24 \\
\hline Electrocardiogram & 169 & $2,900.04$ & 127 & $2,179.32$ & 42 & 24,8 & 720.72 \\
\hline Chest X-ray & 43 & 559.00 & 11 & 143.00 & 32 & 74,4 & 416.00 \\
\hline Echocardiogram & 7 & 509.20 & 4 & 290.97 & 3 & 42,8 & 218.22 \\
\hline Stress test & 4 & 184.80 & 1 & 46.20 & 3 & 75,0 & 138.60 \\
\hline Total & 1.075 & $8,451.97$ & 475 & $4,169.01$ & 600 & 55,8 & $4,295.98$ \\
\hline
\end{tabular}

*CBC: complete blood count; Coagulogram: prothrombin activity, PT, INR, PTT. **Ionogram: Na, K, Cl.

Table V - Comparison between the Total Costs of Surgeon-guided Preoperative Care and Those Based on Preanesthesia Evaluation in the 200 Patients Evaluated

\begin{tabular}{lllllll}
\hline & \multicolumn{2}{l}{ Surgeon-guided care } & \multicolumn{2}{l}{ Preanesthesia evaluation } & \multicolumn{2}{l}{ Difference } \\
\hline & $\mathrm{n}$ & Costs $(\mathrm{R} \$)$ & $\mathrm{n}$ & Cost $(\mathrm{R} \$)$ & $\mathrm{n}$ & $\mathrm{Cost}(\mathrm{R} \$)$ \\
Ancillary exams & 1075 & $8,451.97$ & 475 & $4,155.98$ & 600 & $4,295.99$ \\
Referrals & 181 & $5,606.38$ & 6 & 198.46 & 175 & $5,407.92$ \\
Preanesthesia consultation & 0 & 0.00 & 200 & $6,173.39$ & -200 & $-6,173.39$ \\
Total & 1256 & $14,058.35$ & 681 & $10,527.83$ & 575 & $3,530.52$ \\
\hline
\end{tabular}

Table VI - Comparison of the Number of Patients According to ASA Physical Classification Performed by the Specialist and Anesthesiologist

\begin{tabular}{llll}
\hline ASA physical status $^{*}$ & Specialist classification & Anesthesiologist classification & Disagreement in classification \\
\hline I & 68 & 62 & 6 \\
II & 98 & 106 & 8 \\
III & 6 & 4 & 2 \\
Total & 172 & 172 & 16 \\
\hline
\end{tabular}

${ }^{*}$ American Society of Anesthesiologists.

from that of the anesthesiologist (Table VI). Comparing the concordance rate by the Kappa test a rate of 0.645 showed concordance between classifications.

Surgeries were not cancelled or postponed, and anesthesia-related complications were not observed in the patients evaluated.

\section{DISCUSSION}

Preanesthesia evaluation (PAE) is fundamental in the preparation of surgical patients, and its advantages have been well established. Cost reduction is one of the benefits of PAE, which have been observed by other authors $5,6,10,11$. Corroborating those studies the present study demonstrated that in comparison to surgeon-conducted preoperative care PAEbased care can result in significant cost reduction.

Despite the low risk of perioperative complications in healthy patients, historically several tests performed before elective procedures became routine all over the world in the second half of the XX Century ${ }^{12,13}$. However, solicitation of a battery of exams for all patients did not bring many useful information and it did not increase the rate of adverse events, besides showing several false-positive results ${ }^{12,14}$. Therefore, from the decade of 1990 on the concern to limit preoperative exams to those that were really indicated according to the clinical condition of the patient arose ${ }^{12}$. Despite this, the excess of preoperative exams still is a reality in several services, and it is indicated as one of the main reasons for unnecessary expenditure ${ }^{14}$.

The objectives of preoperative exams are the following: to identify a disease or disorder that can affect anesthesia, verify or evaluate an already known disease, or alternate therapy that could affect the anesthetic plan, and to formulate alternatives for postoperative care 1 . In order to define the exams that are indicated, one should consider: relevance of the abnormality observed, prevalence of specific diseases in symptomatic or asymptomatic patients, and sensitivity and specificity 
as well as the cost of those exams ${ }^{14}$. Practical guides to rationalize the request of preoperative exams have been used as a resource to reduce the number of those tests without hindering patient safety ${ }^{5}$. In the present study, the directives of the anesthesiology service of the institution elaborated based on prior publications ${ }^{1,5,8,9}$ were adopted.

Considering that the request of preoperative exams is aimed at identifying diseases or conditions that might compromise perioperative treatment ${ }^{15,16}$, its indication in healthy patients is controversial. Narr et al. ${ }^{17}$ followed-up 1,044 healthy patients who underwent elective surgeries without preoperative ancillary exams and they did not observe perioperative morbidity or mortality. In the present study, those exams were considered unnecessary in 37 patients (18.5\%) all of them who were classified as ASA I. Considering that 82 patients (41\%) were classified as ASA I, it was observed that preoperative exams were unnecessary in $45 \%$ of healthy patients to undergo the procedures evaluated. We also observed that $55.8 \%$ of the exams were not indicated, a similar result to the $60 \%$ observed by Kaplan et al. ${ }^{18}$ in a retrospective review that included 2,000 patients.

Prior studies indicated that when preoperative care is the responsibility of the surgeon a greater number of exams and referrals, besides postponemt and cancelations of surgeries were observed $3,18,19$. In the present study, whenever preoperative care is a responsibility of the surgeon we observed an excess of exams and referrals. However, postponement was not necessary according to the evaluation of the anesthesiologist, although some patients did not perform all exams considered to be indicated. This was probably because once patients who had been admitted to the hospital prior to the surgery had been excluded the study population was composed mainly by patients ASA I or II who underwent small or medium size surgeries. Contrary to other guides that contemplate the size of the surgery ${ }^{8}$, the directives adopted in this study do not, suggesting that for the study population some exams considered to be indicated could be unnecessary. If the size of the surgery is considered, the criteria are more rigid and greater their impact on costs.

The proper use of health resources has generated extensive debates and great interest among governmental agents and administrators. Preoperative medicine has been seen as a potential target for cost reduction, especially regarding ancillary exams. The objective is to guarantee that the necessary exams are performed and to avoid unnecessary tests ${ }^{12}$. Some authors observed cost reduction associated with a preoperative care conducted by the anesthesiologist 11,20. Similarly, the present study demonstrated that the anesthesiologist-oriented preoperative care can result in a significant economy of approximately $50 \%$ of the costs of exams and $25 \%$ of global costs. Comparing the surgeon and anesthesiologist care, other authors observed a $37 \%$ reduction in the number of exams representing a $38 \%$ economy with exams ${ }^{21}$. In the present study the main unnecessary exams included coagulogram, complete blood count, serum BUN, and blood glucose levels. Note that in a study undertaken 14 years ago 20 the authors reported similar results, especially regarding the coagulogram, whose indication was reduced by $82.3 \%$, close to the $86 \%$ observed in the present study. The over solicita- tion of preoperative coagulogram demonstrates the difficulty of physicians to dismiss this exam, possible due to the fear of hemorrhagic complications or legal problems, although criteria for this exam are well established.

Cost reduction in costs is also related to the number of referrals during the preoperative care of surgical patients. Referrals of patients to several specialists are oftentimes dispensable. Based on judicious clinical evaluation, the anesthesiologist can reduce some of those referrals. If the responsibility of referring patients is transferred to the anesthesiologist, one can see a reduction of $73 \%$ in them ${ }^{19}$. In the present study, this reduction would have been of $96.8 \%$. This higher index is most certainly due to the fact that only $2 \%$ of the patients had severe comorbidities (physical status ASA equal or higher than III), while in the other study it was $59 \%$.

Disagreements in ASA classification between the anesthesiologist and other physicians was another data evaluated in this study. This disagreement was observed in $9.6 \%$ of the patients. This suggests different interpretations of this classification, although the percentage of discordances was low in comparison to prior studies performed with groups of anesthesiologists ${ }^{22-24}$. Owens et al. ${ }^{23}$ observed an index close to $40 \%$ and that factors such as age, obesity, a history of myocardial infarction, and anemia increase this discordance rate. This scenery suggests that when evaluating clinical problems the ASA classification by itself cannot be satisfactory to describe the physical status of the patient ${ }^{23}$. However, in the aforementioned studies physical status classification was performed based on clinical reports. On the contrary, in the present study patients were classified in a medical consultation which might justify the higher concordance rate. The limitations of the ASA classification generate discussion on its validity and usefulness, as well as the need of a new classification ${ }^{24}$. Nevertheless, from the results of the present study whose methodology more closely resembles the real use of this classification we can consider that direct contact with the patient including the physical exam improves its applicability.

Our study has limitations. Despite the indication of exams by the anesthesiologist had been based on defined criteria, the PAE was performed on the day of the surgery and not as an outpatient, which is the ideal. Besides, patients whose preoperative preparation is oftentimes performed in the hospital were excluded from the study resulting in lower number of critical patients. Finally, we only selected patients from a given health insurance carrier, who do not routinely undergo outpatient PAE. Therefore, it is possible that those are limiting factors on the applicability of the results to other groups of patients.

The key to promote a cost-effective preoperative evaluation includes the education of the physician and changes in clinical practice, implantation of practical guides, a trained staff, task division, economic analysis, and directed resources ${ }^{9}$. From the results of the present study, we conclude that anesthesiologist-oriented preoperative care based on defined criteria can result in significant cost reduction when compared to that of the surgeon. This reduction was related mainly to a reduction in the number of ancillary exams requested in the preoperative care. 
07. ASA - New classification of physical status. Anesthesiology, 1963;24:111.

08. Fleisher LA, Beckman JA, Brown KA et al. - ACC/AHA 2007 Guidelines on perioperative cardiovascular evaluation and care for noncardiac surgery. J Am Coll Cardiol, 2007;50:e159-241.

09. NCCAC - Preoperative tests, the use of routine preoperative tests for elective surgery-Evidence, methods and guidance. London: NICE, 2003. Disponível em: <www.nice.org.uk/Guidance/CG3>.

10. Fischer SP - Cost-effective preoperative evaluation and testing. Chest, 1999;115(5suppl):96S-100S.

11. Starsnic MA, Guarnieri DM, Norris MC - Efficacy and financial benefit of an anesthesiologist-direct university preadmission evaluation center. J Clin Anesth, 1997;9:299-305.

12. Foss JF, Apfelbaum J - Economics of preoperative evaluation clinics. Curr Opin Anaesthesiol, 2001;14:559-562.

13. Sharma GK, Sharma SB, Shaheen WH - Preoperative Testing. Contributor Information and Disclosures 2009.

14. Pasternak LR - Preoperative laboratory testing: general issues and considerations. Anesthesiol Clin North America, 2004; 22:13-25.

15. Mathias LA, Guaratini AA, Gozzani JL et al. - Exames complementares pré-operatórios: análise crítica. Rev Bras Anestesiol, 2006;56:658-668.

16. Robbins JA, Mushlin AL - Preoperative evaluation of healthy patient. Med Clin North Am 1979;294:1145-1156.

17. Narr BJ, Warner ME, Schroeder DR et al. - Outcomes of patients with no laboratory assessment before anesthesia and a surgical procedure. Mayo Clin Proc, 1997;72:505-509.

18. Kaplan EB, Sheiner LB, Boeckmann AJ et al. - The usefulness of preoperative laboratory screening. JAMA, 1985; 253:3576-3581.

19. Parker BM, Tetzlaff JE, Litaker DL et al - Redefining the preoperative evaluation process and the role of anesthesiologist. J Clin Anesth, 2000;12:350-356

20. Ficher SP - Development and effectiveness of an anesthesia preoperative evaluation clinic in a teaching hospital. Anesthesiology, 1996;85:196-206.

21. Finegan BA, Rashiq S, McAlister FA et al - Selective ordering of preoperative investigations by anesthesiologists reduces the number and cost of tests. Can J Anaesth, 2005;52:575-80.

22. Power LM, Thrackray NM - Reduction of preoperative investigations with the introduction of an anaesthetist- led preoperative assessment clinic. Anaesth Intensive care, 1999; 27;481-488.

23. Owens WD, Felts JA, Spitznagel Jr EL - ASA physical status classifications: a study of consistency of ratings. Anesthesiology, 1978;49:239-243.

24. Haynes SR, Lawler PG - An assessment of the consistency of ASA physical status classification allocation. Anaesthesia, 1995;50:195199.

25. Mak PH, Campbell RC, Irwin MG - The ASA Physical Status Classification: inter-observer consistency. American Society of Anesthesiologists. Anaesth Intensive Care, 2002;30:633-640.

\section{REFERÊNCIAS / REFERENCES}

01. American Society of Anesthesiologists Task Force on Preanesthesia Evaluation - Practice advisory for preanesthesia evaluation: a report by the American Society of Anesthesiologists Task Force on Preanesthesia Evaluation. Anesthesiology, 2002;96:485-496.

02. Klopfenstein CE, Forster A, Van Gessel E - Anesthetic assessment in an outpatient consultation clinic reduces preoperative anxiety. Can J Anaesth, 2000; 47:511-515.

03. Mendes FF, Mathias LAST, Duval Neto GF et al - Impacto da implantação de clínica de avaliação pré-operatória em indicadores de desempenho. Rev Bras Anestesiol, 2005;45:175-187.

04. Barnes PK, Emerson PA, Hajnal S et al. - Influence of an anaesthetist on nurse-led, computer-based, pre-operative assessment. Anaesthesia, 2000; 55:576-580.

05. Ferrando A, Ivaldi C, Buttiglieri A et al. - Guidelines for preoperative assessment: impact on clinic practice and costs. Int $\mathrm{J}$ Qual Health Care, 2005;17:323-329.

06. Allison JG, Bromley HR - Unnecessary preoperative investigations: evaluation and cost analysis. Am Surg, 1996;62:686-689.

Resumen: Issa MRN, Isoni NFC, Soares AM, Fernandes ML - Evaluación Preanestésica y Reducción de los Costes de la Preparación del Preoperatorio.

Justificativa y objetivos: La evaluación preanestésica (EPA), es fundamental para la preparación del paciente quirúrgico. Entre sus muchas ventajas tenemos la reducción de los costes con la preparación del preoperatorio. Aunque algunos estudios previos hayan constatado ese beneficio, no es correcto decir que él se pueda aplicar adecuadamente a nuestro medio. El objetivo de este estudio fue comparar los costes de la preparación del preoperatorio realizado por el cirujano con los costes estimados a partir de la EPA. En paralelo, comparamos la clasificación del estado físico de la American Society of Anesthesiologists (ASA) determinada por el anestesiólogo o por otros especialistas.

Método: Doscientos pacientes candidatos a procedimientos quirúrgicos o diagnósticos electivos, cuya preparación preoperatoria estu- 
vo orientada por el cirujano, se sometieron a la EPA después de su ingreso. El anestesiólogo determinó los exámenes complementarios o las consultas especializadas pertinentes para cada paciente. Se comparó el número y los costes de los exámenes o consultas indicados por el anestesiólogo con los realizados durante la preparación del preoperatorio. También comparamos la clasificación de la ASA determinada por el anestesiólogo o por el médico que realizó la consulta especializada.

Resultados: De los 1.075 exámenes complementarios realizados $55,8 \%$ no estaban indicados, lo que equivalió a una fracción de un $50,8 \%$ del coste total con los exámenes. El anestesiólogo consideró que 37 pacientes (18,5\%) no necesitarían realizar exámenes.
El coste de la preparación orientada por el cirujano fue un 25,11\% mayor que el coste estimado a partir de la evaluación preanestési$\mathrm{ca}$, siendo ésa la diferencia entre los costes estadísticamente significantes: $(p<0,01)$. Se registró una discordancia en la clasificación de la ASA en $9,3 \%$ de los pacientes evaluados por el experto.

Conclusiones: La preparación del preoperatorio con base en la evaluación preanestésica de criterio puede resultar en una significativa reducción de los costes cuando se le compara a la preparación orientada por el cirujano. Se observó una buena concordancia en la determinación de la puntuación de la ASA.

Descriptores: AVALIACIÓN: Preanestésica; EXÁMENES COMPLEMENTARES: Costes. 